\title{
BMJ Open Lockdown and non-COVID-19 deaths: cause-specific mortality during the first wave of the 2020 pandemic in Norway: a population-based register study
}

Guttorm Raknes (1D , ${ }^{1,2}$ Marianne Sørlie Strøm, ${ }^{1,3}$ Gerhard Sulo, ${ }^{4}$ Simon Øverland, ${ }^{4,5}$ Mathieu Roelants, ${ }^{6}$ Petur Benedikt Juliusson ${ }^{1,7}$

To cite: Raknes G, Strøm MS, Sulo G, et al. Lockdown and non-COVID-19 deaths: causespecific mortality during the first wave of the 2020 pandemic in Norway:

a population-based register study. BMJ Open 2021;11:e050525. doi:10.1136/ bmjopen-2021-050525

- Prepublication history and additional supplemental material for this paper are available online. To view these files, please visit the journal online (http://dx.doi.org/10.1136/ bmjopen-2021-050525)

Received 25 February 2021 Accepted 16 November 2021
Check for updates

(C) Author(s) (or their employer(s)) 2021. Re-use permitted under CC BY-NC. No commercial re-use. See rights and permissions. Published by BMJ.

For numbered affiliations see end of article.

Correspondence to Dr Guttorm Raknes; guttorm.raknes@fhi.no

\section{ABSTRACT}

Objective To explore the potential impact of the first wave of COVID-19 pandemic on all cause and cause-specific mortality in Norway.

Design Population-based register study.

Setting The Norwegian cause of Death Registry and the National Population Register of Norway.

Participants All recorded deaths in Norway from March to May from 2010 to 2020.

Main outcome measures Rate (per 100 000) of all-cause mortality and causes of death in the European Shortlist for Causes of Death from March to May 2020. The rates were age standardised and adjusted to a $100 \%$ register coverage and compared with a $95 \%$ prediction interval (PI) from linear regression based on corresponding rates for 2010-2019.

Results 113710 deaths were included, of which 10226 were from 2020. We did not observe any deviation from predicted total mortality. There were fewer than predicted deaths from chronic lower respiratory diseases excluding asthma (11.4, 95\% PI 11.8 to 15.2$)$ and from other nonischaemic, non-rheumatic heart diseases $(13.9,95 \% \mathrm{PI}$ 14.5 to 20.2). The death rates were higher than predicted for Alzheimer's disease (7.3, 95\% PI 5.5 to 7.3 ) and diabetes mellitus (4.1, 95\% PI 2.1 to 3.4 ).

Conclusions There was no significant difference in the frequency of the major causes of death in the first wave of the 2020 COVID-19 pandemic in Norway compared with corresponding periods 2010-2019. There was an increase in diabetes mellitus and Alzheimer's deaths. Reduced mortality due to some heart and lung conditions may be linked to infection control measures.

\section{INTRODUCTION}

The first two Norwegians deaths linked to COVID-19 in Norway were recorded on 12 March 2020. ${ }^{1}$ The same day the Norwegian government imposed the most comprehensive infection control measures since World War II (text box 1). ${ }^{2}$

Total mortality figures indicate no excess mortality in Norway in spring $2020 .^{3}$ However, total mortality figures do not reflect potential
Strengths and limitations of this study

- The study covers all deaths in Norway during the first wave of the 2020 pandemic.

- The study was designed to disclose changes in the frequency of non-COVID-19 death causes compared with 2010-2019, potentially indicating links to strict infection control measures.

- A higher proportion of missing information on causes of death is a limitation that was adjusted for.

- A higher proportion of deaths at home and the introduction of an electronic death certificate were potential sources of bias.

changes in the cause composition of deaths or specific changes for certain causes.

There are concerns that the lockdown and social distancing measures may cause unintended negative consequences for public health and mortality. ${ }^{4}$ Some of the specific concerns relate to patients potentially avoiding contact with health services, even for potentially critical symptoms such as chest pain or signs of stroke, ${ }^{5}$ or increased suicide rates due to worsening of mental illness in the context of social distancing. ${ }^{6}$ On the other hand, social distancing may contribute to fewer infectious diseases in general, such as pneumonia and influenza. The general health of patients with chronic conditions such as heart disease, dementia and diabetes, may also be more stable in the absence of acute infections, leading to lower hospitalisation rates and maybe mortality.

In most western European countries, it is likely that a high excess mortality due to COVID-19 has masked trends in mortality due to other causes which makes it difficult to assess the effect of restrictions or lockdowns. In Norway, substantial lockdown measures were in place, even though the COVID-19 mortality was low, and unexpected changes in 
Box 1 Measures imposed by the Norwegian government on 12 March 2020 to limit the spread of the SARS-CoV-2 virus

Schools, universities, and kindergartens, shops, and services considered non-essential were shut down.

Mandatory 14-day quarantine for all persons entering Norway from countries with a high transmission rate, or after exposure to potential contagion.

People were told to isolate themselves and, if possible, to get tested at the slightest sign of respiratory infection.

General calls for hand hygiene, to keep a distance of at least two metres in the public space, to work from home whenever possible and to avoid using public transport.

cause-specific mortality rates could thus be attributed to the infection control measures.

In this study, we used data from the Norwegian Cause of Death Registry to explore whether cause-specific mortality in Norway during the first wave of the COVID-19 pandemic (March to May 2020) was different from that observed during the same months in the preceding years.

\section{METHODS}

We conducted an observational, population-based register study.

Data were obtained from the Norwegian Cause of Death Registry and included information from all death certificates received by 11 December 2020 .

The study included all deaths occurring from 1 March 2020 to 31 May 2020, and all deaths from 1 March to 31 May in the years 2010-2019 as reference. The data included Norwegian citizens who died abroad, but not foreign citizens who died in Norway.

Main outcomes were mortality rates (per 100000 inhabitants) for all items on the 2012 European Shortlist for Causes of Death. The causes of death in the shortlist are organised in main headings (level 1 codes, eg, cancer, external causes and organ-specific causes), and further in more detailed level 2 codes and level 3 codes for some specific subcategories (see online supplemental table 1). ${ }^{7}$ External causes are deaths not caused by disease, and include accidents, intentional and non-intentional injuries and poisonings. Analyses were performed for allcause mortality, deaths caused by diseases and external causes, the 17 level- 1 causes, on all 35 level-2 causes and all 31 level-3 causes. We present results of analyses for all level 2 and 3 causes of death from the European shortlist when the observed age-standardised rates were outside the $95 \%$ prediction interval. Special attention was given to suicide rates, as it was feared that this rate would increase during the lockdown. For respiratory diseases, we calculated rates both including and excluding COVID-19.

The cause of death is reported by a physician to the Norwegian Cause of Death Registry and the Population Register by completing and mailing an international death certificate (1993 version $)^{8}$ or online by submitting an electronic death certificate. ${ }^{9}$

The International Classification of Diseases, tenth revision, (ICD-10) code of the cause of death in the register is determined from the death certificate by an automated coding system (Iris) that is based on the Automatic Classification of Medical Entry software. ${ }^{10}{ }^{11}$ When needed, the cause of death is manually evaluated by trained staff from the Norwegian Cause of Death Registry. The term 'Cause of Death' used throughout this manuscript is equivalent to the 'underlying cause of death' as defined by WHO. ${ }^{12}$

\section{Bias}

Although it is mandatory by law to report all deaths to the Norwegian Cause of Death Registry, not all deaths are captured. In some cases, no death certificate is submitted, or some of the involved parties may fail to forward the document to the register. Approximately $2 \%$ of death certificates are missing in a typical year. Also, a portion of death certificates is submitted with a delay of several months. Data for 1 year are considered complete by the annual publication of the official annual Norwegian cause of death statistics. The data used in this study were retrieved several months before the publication of the 2020 annual statistics, and this contributed to a higher proportion of missing causes of death. We cannot rule out that some causes of death were over- or underrepresented in death certificates received by the register after we extracted data for this study. We do not believe that the biases are sufficient to affect our main findings.

Efforts were made to reduce number of missing causes of death in the 2020 data. The introduction of the digital death certificate contributed to speeding up the logistics, as the register receives electronic certificates within 24 hours. Since the cause of death is more often missing for persons who died abroad, we also analysed the data excluding these.

We were aware of an increase in the number of deaths at home (outside hospitals and nursing homes), probably secondary to the infection control measures. This could lead to bias, for example, due to a larger proportion of death certificates submitted by a general practitioner. Electronic death certificates were available before, during and after the first wave of the pandemic in 2020, and differences between the electronic and paper registration forms could lead to systematic differences in the reporting of cause of death. Before 2020, death certificates were almost exclusively paper based.

The pandemic itself may also have influenced how doctors determined causes of death on the death certificate. For example, COVID-19 may have changed the level of precision for respiratory causes of death.

\section{Statistical methods}

Age-standardised death rates for the period March-May 2020 were compared with those of the same period during years 2010-2019. Age-standardised mortality rates were computed by the direct standardisation method, using 
5-year age strata and the European Standard Population of 2013 as standard population. ${ }^{13}$ The 'at-risk' population was defined as the Norwegian population according to Statistics Norway on 1 January of each year. ${ }^{14}$

The age-standardised rates were adjusted to $100 \%$ coverage for all years to reduce the impact of missing data when comparing different years. We adjusted each cause of death group, subgroup or diagnosis with a proportion of missing data, corresponding to the proportion the outcome made up of the total non-missing data for each year. The death rates used for the analyses are thus agestandardised, adjusted data, but raw rates not adjusted for missing data are also represented in figures.

Observed rates of all cause or disease specific causes of mortality in March-May 2020 were compared with projections based on the same causes during the same months in 2010-2019. Projections were estimated with linear regression and reported as a $95 \%$ prediction interval. Rates outside this interval were considered as a statistically significant change. A Durbin-Watson test was used to detect autocorrelation among the annual observations.

The missing cause of death rate was determined by comparing the number of cases with known cause of death with the number of registered deaths in the National Population Register. It is mandatory to be listed in the Population register, and comparison is possible due to a unique personal identification number assigned all Norwegian citizens. We assumed causes of death were missing at random. To assess whether missing or delayed death certificates introduced bias, we examined the distribution of age and sex of the deceased and the location of death (home, hospital, or nursing home). A similar comparison was made for causes of deaths based on electronic vs paper-based death certificates.

It is statutory that all deaths that include Norwegian citizens must be registered with the cause of death in the Norwegian Cause of Death Registry. ${ }^{15}$ Prior consent to the storage of personal data in the register is not obtained, and it is not possible to opt out. Approval from the ethics committee or privacy ombudsman for research was neither required nor expedient.

\section{Patient and public involvement}

The study was partly initiated due to questions from the press and public. Patients and the public were not involved in the development and conduct of the study or interpretation or presentation of the results. It is not possible for either researchers or the general population to influence which parameters are registered in the Norwegian Cause of Death Registry. All data not presented here are freely available on request.

\section{Data sharing statement}

All analyses were performed on aggregated data, we did not have access to directly or indirectly person identifiable data at any time.

The main analyses are based on cause of death data retrieved on 11 December 2020, these data are included
Table 1 Characteristics of persons dying from March-May, 2010-2020

\begin{tabular}{lll}
\hline & 2010-2019 & 2020 \\
\hline Mean age $( \pm$ SD) & $78.7( \pm 15.2)$ & $78.7( \pm 14.8)$ \\
Median age (IQR) & $82(17)$ & $82(17)$ \\
$\mathrm{N}(\%)$ females & $52910(51.1)$ & $4909(50.8)$ \\
$\mathrm{N}(\%)$ external cause & $6394(6.3)$ & $598(6.2)$ \\
$\mathrm{N}(\%)$ death at home & $14214(14.0)$ & $1554(16.1)$ \\
$\mathrm{N}$ all deaths & 103484 & 10226 \\
\hline
\end{tabular}

in online supplemental table 1. Updated data from the Norwegian Cause of Death Registry are publicly available online (http://statistikkbank.fhi.no/dar/, in Norwegian only). ${ }^{16}$ This website is updated regularly, and late incoming death certificates provide a gradually improving coverage.

Data on the number of death certificates submitted electronically are not publicly available, but these will be made available on request. Weekly death statistics from the National Population Register can be accessed via Statistics Norway's webpages (https:// www.ssb.no/befolkning/artikler-og-publikasjoner/ her-finner-du-ukentlige-tall-pa-antall-dode).

\section{RESULTS}

In total, 113710 deaths were identified in the months March, April, May since 2010. There were 216 cases of COVID-19 as underlying cause of death.

Overall, the cause of death was missing in 2286 cases $(2.0 \%)$. In 2020 the cause of death was unknown in 568 cases $(5.6 \%$ ), including 131 (out of a total of 133) deaths that occurred abroad.

Patient characteristics for deaths in data are presented in table 1.

Rates of all causes, diseases, and level-1 European shortlist causes of death are presented in table 2 while rates of all (levels 1-3) European shortlist causes of death are presented in online supplemental table 2. Observations for all causes, diseases and external causes are presented in figure 1, and for the most frequent level 1 causes (cancer, cardiovascular diseases and respiratory diseases with and without COVID-19) in figure 2. Causes of death for which the observed age-standardised rate fell outside the prediction interval are presented in table 3 and in figure 3. Suicide rates are found in figure 4 . There was a lower than predicted rate for other heart diseases $(-19.7 \%)$ and other chronic lower respiratory diseases $(-13.6 \%)$ (table 3, figure 2). There was a higher-than-expected rate for diabetes mellitus (49.9\%) and Alzheimer's disease $(14.9 \%)$ (table 3, figure 3). Among the rarer causes of death there was a higher-than-predicted rate for oesophageal cancer, non-malignant neoplasms and certain conditions originating in the perinatal period. The suicide rate did not deviate significantly from the projection based 


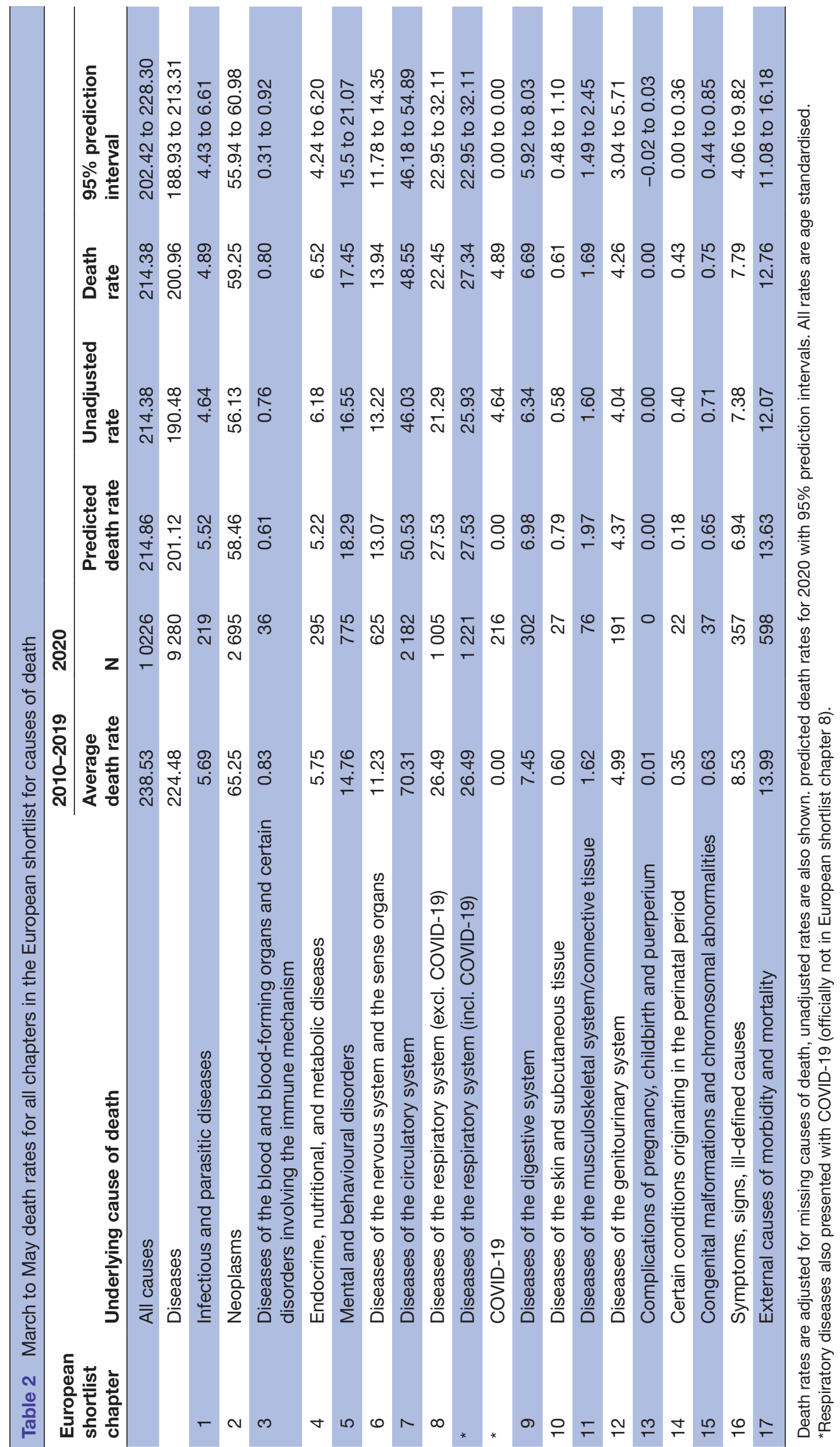




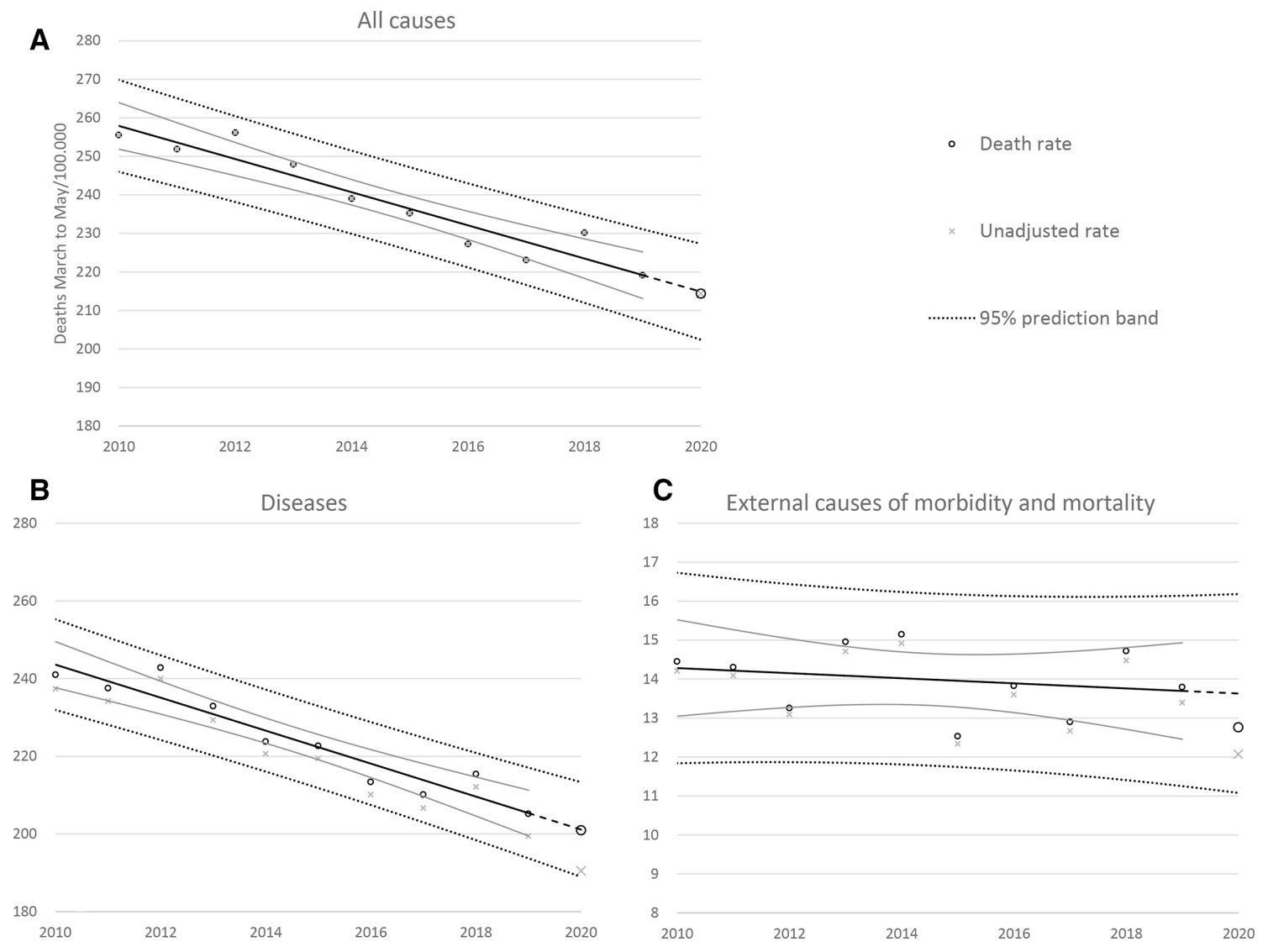

Figure 1 Observed and predicted death rates (linear) with 95\% prediction bands for all-cause mortality (A), total mortality excluding external causes (B) and mortality due to external causes (C).

on 2010 and 2019 (figure 3). This was also the case for all other external causes, including traffic accidents. No significant autocorrelation was observed.

Characteristics of persons with or without known cause of death, death at home and death elsewhere, and cause of deaths reported electronically or with a paper-based death certificate are presented in online supplemental table 3. Age and sex distribution were almost identical in cases with or without known cause of death, and in digital and paper-based death certificates. Among deaths at home, median age was 9 years lower, there was a lower proportion females and external causes of death were more frequent compared with deaths elsewhere.

\section{DISCUSSION}

\section{Principal findings}

In this analysis of mortality during the first wave of the COVID-19 pandemic in Norway, we observed no excess mortality and no substantial changes in the rates for neoplasms, cardiovascular disease, suicide or other external causes including traffic accidents. There was a lower than predicted death rate for respiratory diseases, which is probably attributable to lower mortality from chronic lung diseases (excluding asthma). The mortality rate was also lower than predicted for other non-ischaemic heart diseases (excluding valvular and rheumatic heart conditions) and higher than predicted for Alzheimer's disease. The observed death rate of diabetes mellitus was $50 \%$ higher than predicted. Within neoplasms, we observed higher than expected rates for oesophageal cancer and benign neoplasms.

\section{Strengths and imitations}

The Cause of Death Registry represent the main source of information for monitoring mortality. The Registry is based on established international coding practices that offer comparability and can be used to examine trends over time. The Norwegian Cause of Death Registry covers all deaths in Norway, and since it is possible to verify and validate its content using other sources, it is regarded as highly reliable. ${ }^{17}$ As in the other Nordic countries, the Norwegian society is characterised by a high degree of trust between citizens and in the authorities. As a result, there is evidence of a high degree of compliance with governmental measures during the pandemic, which has probably contributed to low coronavirus transmission and death rates during the pandemic. ${ }^{18}$ There is thus reason to believe that Norway is well suited for studies on the effects of population-based infection control measures.

Although death registers typically cover the whole population, they are prone to bias due to incomplete information on individual cases. Our main concern was bias due to missing or late incoming death certificates. As shown in online supplemental table 3, descriptive characteristics 
A

Diseases of the respiratory system

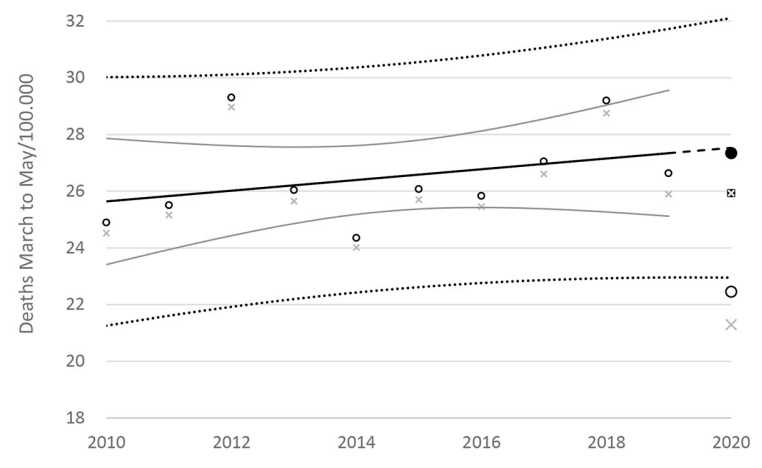

- Death rate

Unadjusted rate

........... $95 \%$ prediction band

- Incl. Covid-19
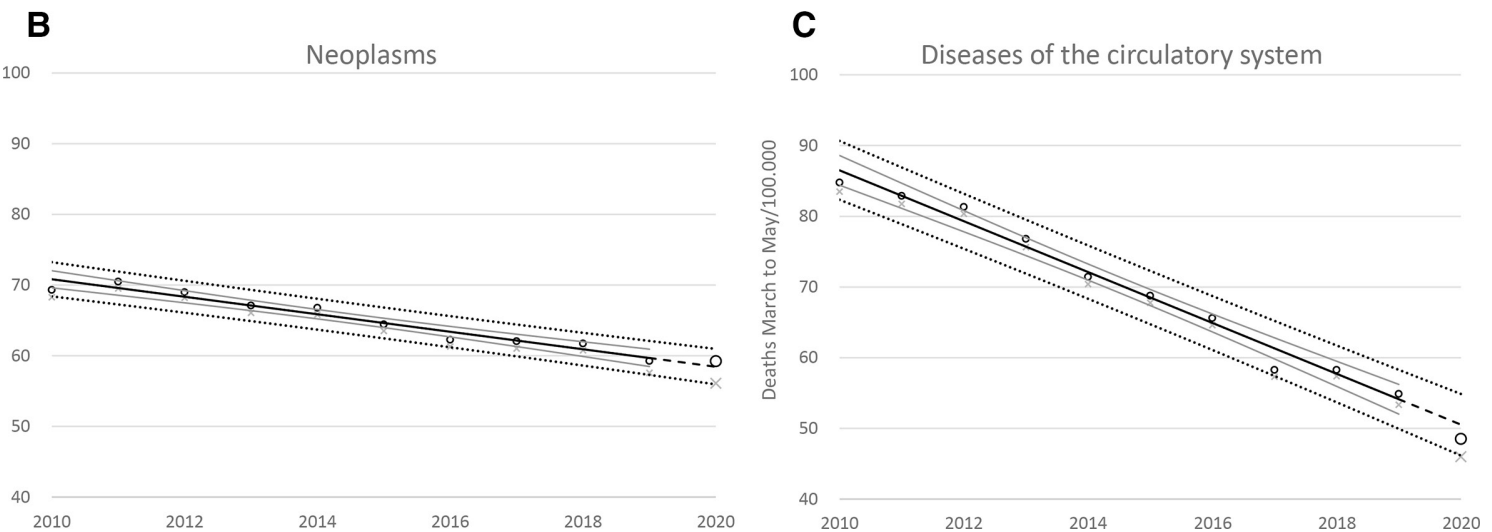

Figure 2 Observed and predicted death rates (linear) with 95\% prediction bands for respiratory diseases (A), neoplasms (B) and cardiovascular diseases causes (C). For 2020, mortality from respiratory diseases is presented both with and without COVID-19.

indicate that average age was 7.4 years higher among deaths with unknown cause in 2020 compared with 20192019. The proportion of females was also higher $(46.8 \%$ in 2020 vs $37.4 \%$ in 2010-2019). Some of these differences may be related to differences in contact with doctors and the healthcare system in general during the pandemic, and to the introduction of electronic death certificates.

It is possible that the pandemic resulted in higher rates of insufficient reporting for certain causes of death. Our adjustment for missing causes did not take cause-specific

Table 3 Observed and predicted mortality from causes of death where the death rate of March to May 2020 deviated statistically significantly from the $95 \%$ prediction interval

\begin{tabular}{|c|c|c|c|c|c|c|c|}
\hline \multirow{2}{*}{$\begin{array}{l}\text { European } \\
\text { shortlist } \\
\text { chapter }\end{array}$} & \multirow[b]{2}{*}{ Underlying cause of death } & \multicolumn{6}{|c|}{ 2010-2019 2020 } \\
\hline & & $\begin{array}{l}\text { Average } \\
\text { death rate }\end{array}$ & $\mathbf{N}$ & $\begin{array}{l}\text { Predicted } \\
\text { death rate }\end{array}$ & $\begin{array}{l}\text { Unadjusted } \\
\text { death rate }\end{array}$ & $\begin{array}{l}\text { Death } \\
\text { rate }\end{array}$ & $\begin{array}{l}95 \% \text { prediction } \\
\text { interval }\end{array}$ \\
\hline 7.2 & Other heart diseases & 20.16 & 622 & 17.33 & 13.20 & 13.92 & 14.50 to 20.17 \\
\hline 8.3 .2 & $\begin{array}{l}\text { Chronic lower respiratory } \\
\text { diseases (excl. Asthma) }\end{array}$ & 13.08 & 509 & 13.48 & 10.79 & 11.38 & 11.80 to 15.15 \\
\hline 6.2 & Alzheimer's disease & 5.23 & 323 & 6.36 & 6.94 & 7.31 & 5.47 to 7.26 \\
\hline 4.1 & Diabetes mellitus & 3.64 & 185 & 2.76 & 3.92 & 4.13 & 2.10 to 3.42 \\
\hline 2.2 & $\begin{array}{l}\text { Non-malignant neoplasms } \\
\text { (benign and uncertain) }\end{array}$ & 1.52 & 87 & 1.37 & 1.84 & 1.94 & 0.80 to 1.93 \\
\hline 2.1.2 & $\begin{array}{l}\text { Malignant neoplasm of } \\
\text { oesophagus }\end{array}$ & 1.22 & 74 & 1.14 & 1.51 & 1.60 & 0.72 to 1.56 \\
\hline 14 & $\begin{array}{l}\text { Certain conditions originating in } \\
\text { the perinatal period }\end{array}$ & 0.35 & 22 & 0.18 & 0.40 & 0.43 & 0.00 to 0.36 \\
\hline
\end{tabular}

Sorted descending after number of deaths. Death rates are adjusted for missing causes of death, unadjusted rates are also shown. All rates are age standardised. 

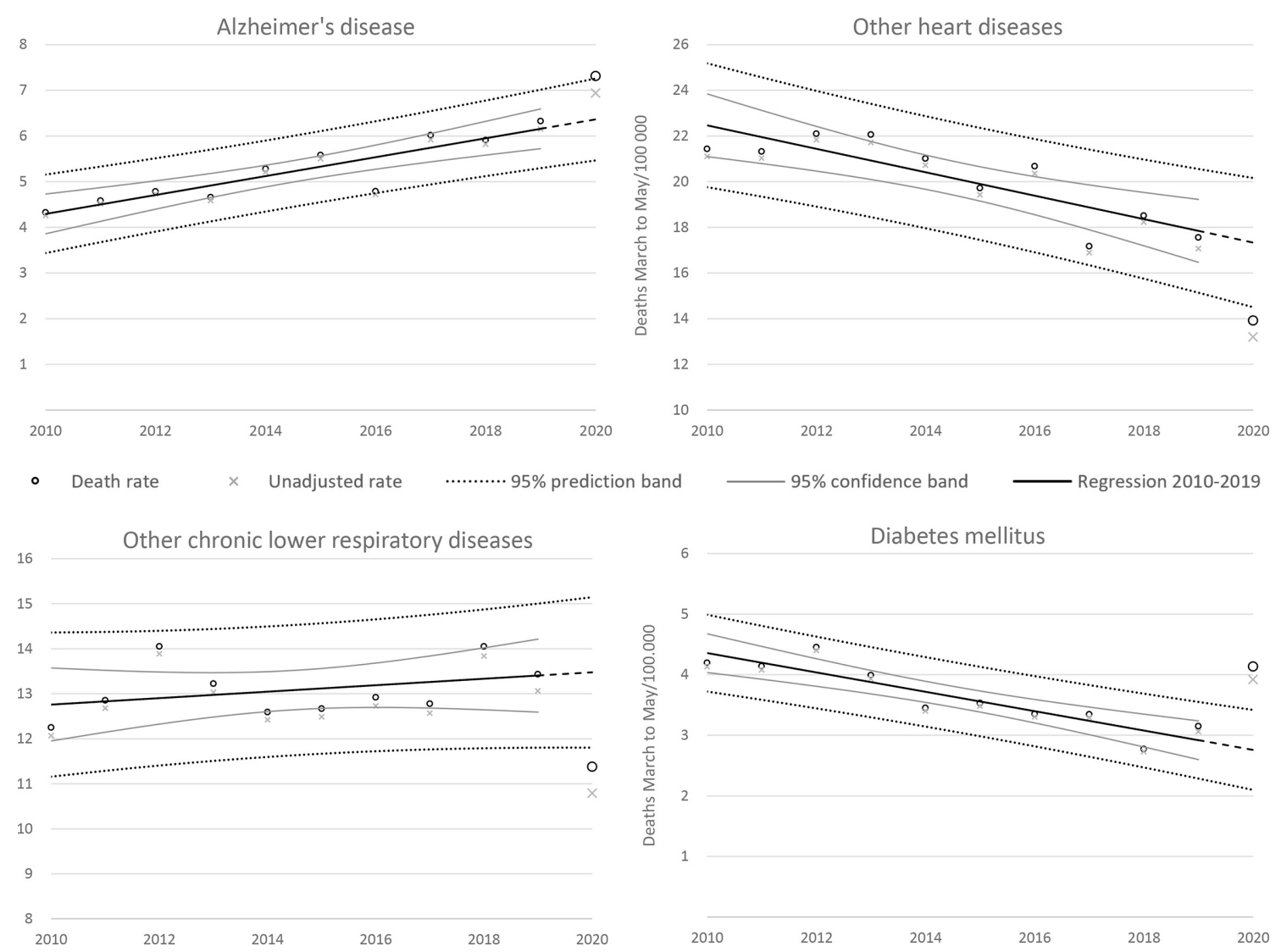

Figure 3 Observed and predicted death rates (linear) with 95\% prediction bands for causes of death with higher or lower rates than expected.

bias into consideration. The underlying cause was missing in $5.6 \%$ of deaths, and we do not believe these had any major influence on the findings.

The number of COVID-19 deaths was low in Norway (only 2.1\% of deaths March to May 2020). In contrast, it is estimated that COVID-19 was the second leading cause of death in Europe in 2020 (18.2\% of all) (https:// www.thinkglobalhealth.org/article/just-how-do-deathsdue-covid-19-stack). It is, therefore, likely that other factors than COVID-19 mortality, such as anti-pandemic measures, caused the observed significant changes in other causes of death.

The proportion of deaths at home from March to May 2020 was $15 \%$ higher than in the same months in 2010-2019. Both age and the proportion of females were considerably lower among deaths at home compared with deaths elsewhere in 2020 (online supplemental table 3), but this was also true in 2010-2019 (data not shown). The absolute increase in deaths at home (200-250 estimated deaths) should not be sufficient to skew the findings significantly. Differences in patient characteristics from electronic and paper-based death certificates were also marginal, and thus unlikely to be a significant source of bias.

Doctors often have limited information about the patient when recording the cause of death on a death certificate, and a subjective assessment may occur. There may have been some systematic changes in the diagnostic practice and determination of the cause of death during the pandemic, especially when it comes to respiratory diseases. A more frequent use of chest X-rays may have biased the rates of the different respiratory causes of death. These effects are difficult to quantify, but we do not believe that the resulting bias is clinically relevant for most causes of death.

Another limitation is the large and diverse number of outcomes. We examined 83 Eropean shortlist causes of deaths without correcting for multiple testing. Even under normal circumstances, it is therefore likely that some rates would fall outside the expected prediction interval. We could have used wider prediction intervals to adjust for multiple comparisons and avoid false positive findings, but this would at the same time increase the probability of a false negative finding. A comparison of the causes of death in table 3 with a $99 \%$ prediction interval, shows that only diabetes mellitus remains significantly outside the predicted range. This means that great care should be taken when interpreting the results.

Presumably, Norwegians abroad were affected by local measures, and their death unrelated to restrictions in Norway. The reporting of deaths abroad is incomplete (typically 5\%-10\% coverage). Among the included deaths occurring abroad in this study, there were only two with known causes. The effects on the main results are negligible. This study only covers 3 months, which may be insufficient to capture all mortality due to the pandemic 


$$
4,5
$$

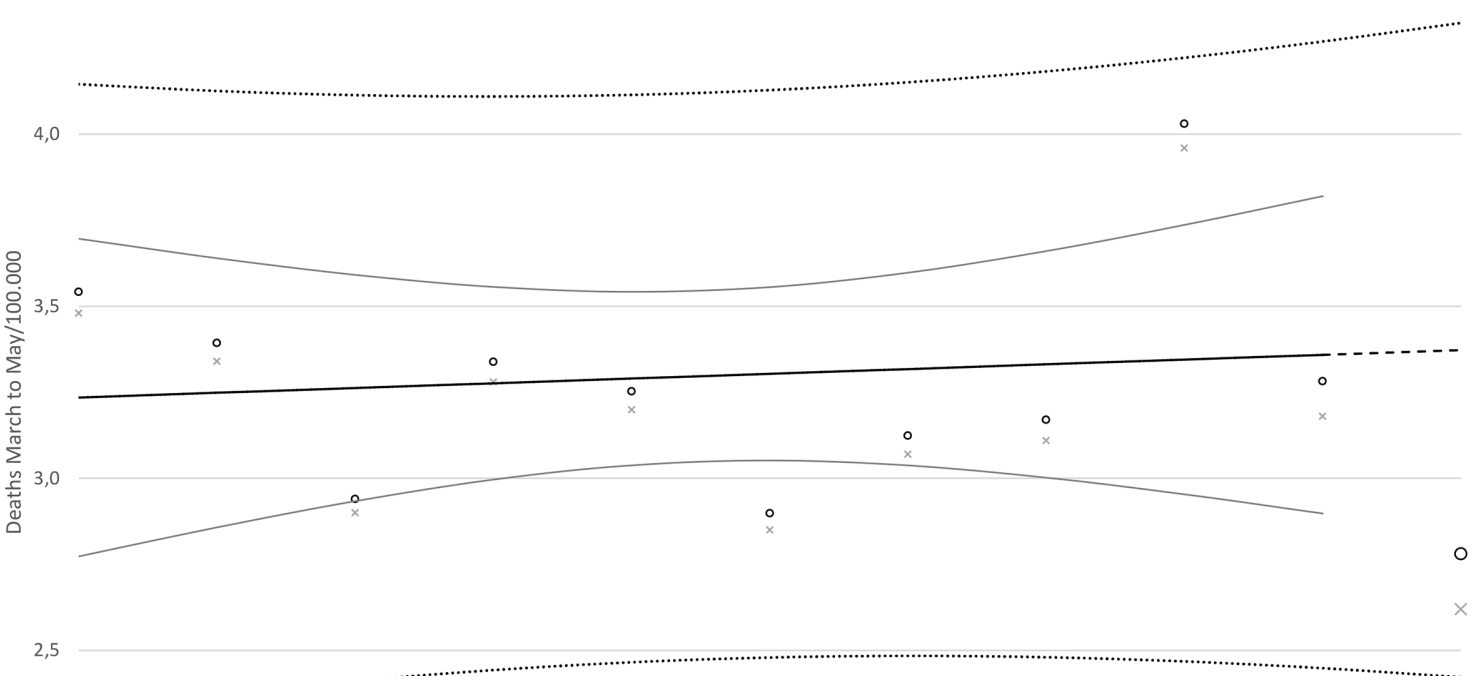

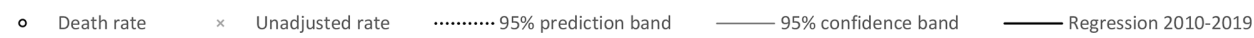

Figure 4 Observed and predicted death rate (linear) with 95\% prediction bands for suicide and intentional self-harm.

restrictions. For example, it is possible that delayed help seeking in the first period of restrictions have caused deaths occurring beyond the observation window of the current study. Future analyses covering a longer time frame and the aftermath of the pandemic may clarify this.

\section{Strengths and weaknesses in relation to other studies and key differences}

We have been unable to identify other studies with similar focus. The SARS-Cov-2 virus was only identified in December 2019, and access to high-quality data with sufficient detail in such a short time is limited. Some studies reported on all-cause mortality, ${ }^{3}{ }^{19}$ in relation to COVID-19 and infection control measures, but data on specific causes of death is usually lacking.

\section{Possible mechanisms and explanations for findings}

Only 216 Norwegians died from COVID-19 in March to May 2020, and the infection rate was also very low. Reports from the Norwegian National Institute of Public Health even showed a lower-than-expected mortality in some of the weeks in the first wave of the pandemic. ${ }^{20}$ It is possible that the number of COVID-19 deaths was underestimated. The death certificates could reflect a such potential of misclassification. However, the number of COVID-19 deaths in Norway has been low. Every death certificate that included any information on COVID-19 was evaluated manually, and additional information was obtained when necessary. In addition to the 216 deaths with COVID-19 as underlying cause, there were only 27 additional certificates where it was mentioned. We, therefore, believe that it is unlikely that SARS-Cov-2 infections had a significant impact on the mortality of other causes in Norway in this period.

The unexpected low death rate from chronic lung diseases could be a consequence of the antipandemic measures. For instance, exacerbations from chronic obstructive pulmonary disease are often caused by respiratory infections. Social distancing and improved hygiene may have been protective, even for non-respiratory diseases. The acute myocardial infarction death rate was the lowest since recordings started in 1970, but this fits into a decades long downward trend. In some other countries where healthcare was more heavily affected by COVID-19, such as in the US, increasing heart disease mortality was seen in March and April 2020. ${ }^{21}$

In contrast, the number of deaths due to Alzheimer's disease has increased since the early 1990s. The observed mortality rate for Alzheimer's disease in 2020 was slightly higher than the upper limit of the prediction interval. Many Alzheimer's patients live in nursing homes where infection control measures were extra strict. There have been concerns that this patient group may have problems 
complying with the infection control measures, and that basic needs of vulnerable patients have been set aside. ${ }^{22}$ Misclassification of COVID-19 deaths as caused by Alzheimer's in this early phase of the pandemic is a potential contributing explanation, since majority of both Alzheimer's (94\%) and COVID-19 deaths (57\%) occurred in nursing homes in 2020. The high proportion of Alzheimer's deaths in nursing homes March to May 2020 (92.9\%) was comparable with 2010-2019 (91.5\%).

The most unexpected and striking finding was the large and significant increase in diabetes mellitus as cause of death (4.1 deaths per 100 000). The increase was 50\% compared with the predicted rate, which is equivalent to an excess of 74 deaths in March to May 2020. One explanation could be that some diabetes patients inappropriately avoided contact with healthcare professionals, which may have contributed to poor blood glucose control. A recent survey among diabetes nurses across Europe confirmed that there are significant physical and psychological problems in their patient populations during COVID-19, and that clinical diabetes services have been disrupted. ${ }^{23}$ We were not able to differentiate between type 1 and type 2 diabetes.

The observed increase in deaths from oesophageal cancer, benign neoplasms and perinatal conditions should be followed closely in the time ahead. However, we find it unlikely that these findings are associated with infection control measures because there is no obvious underlying mechanism, including a special tendency to avoid health services for these conditions. These causes are also rare, and therefore more prone to become outliers in a study with many outcomes. There are reports that the attendance to hospitals was lower during the pandemic, and that this resulted in higher mortality. ${ }^{24}$ This also includes cancer. Our study covers the first 3 months of the pandemic, and it is unlikely that low attendance should be reflected in cancer mortality at this early stage. The perinatal causes were $140 \%$ higher than predicted, but there were only 22 deaths. Deaths due to oesophageal cancer and non-malignant neoplasms were only marginally higher than the upper limit of the $95 \%$ prediction interval.

We did not find an increased suicide rate, but the observation window of our study is limited to the first 3 months of the pandemic in Norway. It is possible that negative effects of the pandemic and social distancing measures will have more impact over time.

So far, COVID-19 is coded separately in the cause of death register, and not as an European shortlist chapter 8 respiratory disease. As seen in figure 2, respiratory disease as cause of death is within the $95 \%$ prediction interval when including COVID-19.

\section{Potential implications for clinicians or policy-makers}

This study did not reveal an alarming increase in the causes of death that could suggest unacceptable negative effects of the infection control measures on public health or mortality, including suicide.
The clinical relevance of the observed changes in cause of death rate is uncertain. Diabetes mellitus may be a notable exception, and extra efforts should be made to monitor diabetes mortality and maybe even improve diabetes care throughout the pandemic.

\section{Unanswered questions and future research}

The current pandemic is caused by a virus that was only discovered in December 2019. We have currently only examined mortality during the first wave in Norway, but similar continuous monitoring is warranted until the population is sufficiently vaccinated. Results from this study highlight the importance to closely monitor morbidity and mortality due to diabetes mellitus in particular.

\section{Author affiliations}

${ }^{1}$ Department of Health Registry Research and Development, Norwegian Institute of Public Health, Bergen, Norway

${ }^{2}$ Raknes Research, Bergen, Norway

${ }^{3}$ Institute of Global Health and Primary Care, Faculty of Medicine, University of

Bergen, Bergen, Norway

${ }^{4}$ Centre for Disease Burden, Norwegian Institute of Public Health, Bergen, Norway

${ }^{5}$ Section for Health Care Collaboration, Haukeland University Hospital, Bergen,

Norway

${ }^{6}$ Department of Public Health and Primary Care, KU Leuven - University of Leuven, Leuven, Belgium

${ }^{7}$ Department of Clinical Science, University of Bergen, Bergen, Norway

\section{Twitter Guttorm Raknes @drguttorm}

Acknowledgements We would like to thank Olaug Margrete Askeland for preparing the data files at short notice.

Contributors GR, MSS, S $\emptyset$ and PBJ initiated the study. The study concept and design were developed by the GR, who also performed the analyses. All authors contributed to the interpretation of the findings. The manuscript was drafted by GR (guarantor), and critically revised by MSS, PBJ, GS, Sø and MR. All authors have all read and approved the final version of the manuscript. The data used (reproduced in online supplemental table 1) were provided by Olaug Margrete Askeland. The authors agreed to be accountable for all aspects of the work in ensuring that questions related to the accuracy or integrity of any part of the work are appropriately investigated and resolved.

Funding The authors have not declared a specific grant for this research from any funding agency in the public, commercial or not-for-profit sectors.

Competing interests None declared.

Patient consent for publication Not applicable.

Ethics approval All analyses were performed on aggregated data, we did not have access to directly or indirectly person identifiable data at any time.

Provenance and peer review Not commissioned; externally peer reviewed.

Data availability statement Data are available on reasonable request. All data relevant to the study are included in the article or uploaded as online supplemental information. All analyses were performed on aggregated data, we did not have access to directly or indirectly person identifiable data at any time.The main analyses are based on cause of death data retrieved on 11 December 2020, these data are included in online supplemental table 1. Updated data from the Norwegian Cause of Death Registry are publicly available online (http://statistikkbank.fhi.no/ $\mathrm{dar} /$, in Norwegian only). This website is updated regularly, and late incoming death certificates provide a gradually improving coverage. Data on the number of death certificates submitted electronically are not publicly available, but these will be made available on request. Weekly death statistics from the National Population Register can be accessed via Statistics Norway's webpages (https://www.ssb.no/ befolkning/artikler-og-publikasjoner/her-finner-du-ukentlige-tall-pa-antall-dode).

Supplemental material This content has been supplied by the author(s). It has not been vetted by BMJ Publishing Group Limited (BMJ) and may not have been peer-reviewed. Any opinions or recommendations discussed are solely those 
of the author(s) and are not endorsed by BMJ. BMJ disclaims all liability and responsibility arising from any reliance placed on the content. Where the content includes any translated material, BMJ does not warrant the accuracy and reliability of the translations (including but not limited to local regulations, clinical guidelines, terminology, drug names and drug dosages), and is not responsible for any error and/or omissions arising from translation and adaptation or otherwise.

Open access This is an open access article distributed in accordance with the Creative Commons Attribution Non Commercial (CC BY-NC 4.0) license, which permits others to distribute, remix, adapt, build upon this work non-commercially, and license their derivative works on different terms, provided the original work is properly cited, appropriate credit is given, any changes made indicated, and the use is non-commercial. See: http://creativecommons.org/licenses/by-nc/4.0/.

ORCID iD

Guttorm Raknes http://orcid.org/0000-0002-3376-6761

\section{REFERENCES}

1 Verdens gang. Coronaviruset. Available: https://www.vg.no/spesial/ 2020/corona/?utm_source=corona-widget\&utm_term=d7\#norway [Accessed Feb 2021].

2 The Norwegian Directorate of Health. Helsedirektoratet har vedtatt omfattende tiltak for å hindre spredning av Covid-19. Available: https://www.helsedirektoratet.no/nyheter/helsedirektoratet-harvedtatt-omfattende-tiltak-for-a-hindre-spredning-av-covid-19 [Accessed Feb 2021].

3 Kontis V, Bennett JE, Rashid T, et al. Magnitude, demographics and dynamics of the effect of the first wave of the COVID-19 pandemic on all-cause mortality in 21 industrialized countries. Nat Med 2020;26:1919-28.

4 Bavli I, Sutton B, Galea S. Harms of public health interventions against covid-19 must not be ignored. BMJ 2020;10:m4074.

5 Feral-Pierssens A-L, Claret P-G, Chouihed T. Collateral damage of the COVID-19 outbreak: expression of concern. Eur J Emerg Med 2020;27:233-4.

6 Lennon JC. What lies ahead: elevated concerns for the ongoing suicide pandemic. Psychol Trauma 2020;12:S118-9.

7 Eurostat. European Shortlist for causes of death, 2012. Available: https://ec.europa.eu/eurostat/ramon/nomenclatures/index.cfm? TargetUrl=LST_NOM_DTL_LINEAR\&IntCurrentPage $=2 \&$ StrNom= COD_2012 [Accessed Nov 2021].

8 World Health Organization. The International form of medical certificate of cause of death. Available: https://crvsgateway.info/TheInternational-Form-of-Medical-Certificate-of-Cause-of-Death 356 [Accessed Nov 2021]

9 Elektronisk dødsmelding. Norwegian Institute of public health. Available: https://www.fhi.no/hn/helseregistre-og-registre/ dodsarsaksregisteret/elektronisk-dodsmelding/ [Accessed Nov 2021].
10 Federal Institute for Drugs and Medical Devices. Iris software, 2021. Available: https://www.bfarm.de/EN/Code-systems/Collaborationand-projects/Iris-Institute/Iris-software/_node.html [Accessed Nov 2021].

11 Lu TH. Using ACME (automatic classification of medical entry) software to monitor and improve the quality of cause of death statistics. J Epidemiol Community Health 2003;57:470-1.

12 World Health Organization. 4.1.2 Underlying cause of death. In: International statistical classification of diseases and related health problems: instruction manual. 5. Geneva, 2016: Vol. 2. P23.

13 European Commission. Eurostat. Revision of the European Standard Population: report of Eurostat's task force. LU: Publications Office, 2013.

14 Norway. 07459: population, by sex and one-year age groups (M) 1986, 2020. Available: https://www.ssb.no/en/statbank/table/07459/ [Accessed Nov 2021].

15 FOR-2001 - $12-21$ - 1476. Forskrift Om innsamling OG behandling AV opplysninger I Dødsårsaksregisteret (Dødsårsaksregisterforskriften, 2001. Available: https://lovdata.no/ dokument/SF/forskrift/2001-12-21-1476 [Accessed Jan 2021].

16 Norwegian Institute of Public Health. Dødsårsaksregisteret statistikkbank. Available: http://statistikkbank.fhi.no/dar/ [Accessed Feb 2021].

17 Phillips DE, Lozano R, Naghavi M, et al. A composite metric for assessing data on mortality and causes of death: the vital statistics performance index. Popul Health Metr 2014;12:14.

18 Conyon MJ, He L, Thomsen S. Lockdowns and COVID-19 deaths in Scandinavia. SSRN Journal 2020.

19 Nørgaard SK, Vestergaard LS, Nielsen J, et al. Real-time monitoring shows substantial excess all-cause mortality during second wave of COVID-19 in Europe, October to December 2020. Euro Surveill 2021;26.

20 Norwegian Institute of public health. Total mortality monitoring. Report week 4/(In Norwegian), 2021. Available: https://www.fhi.no/ globalassets/dokumenterfiler/influensa/influensaovervaking/0421overvaking-av-totaldodelighet-2021-uke-4.pdf [Accessed Feb 2021].

21 Kelly G, Petti S, Noah N. Covid-19, non-Covid-19 and excess mortality rates not comparable across countries. Epidemiol Infect 2021;149:e176.

22 Neerland BE. The pandemic of the vulnerable, 2020. Tidsskr nor Legeforen. Available: https://tidsskriftet.no/en/2020/08/leder/ pandemic-vulnerable [Accessed Nov 2021].

23 Forde R, Arente L, Ausili D, et al. The impact of the COVID-19 pandemic on people with diabetes and diabetes services: a panEuropean survey of diabetes specialist nurses undertaken by the foundation of European nurses in diabetes survey Consortium. Diabet Med 2021;38:e14498.

24 Lai AG, Pasea L, Banerjee A, et al. Estimated impact of the COVID-19 pandemic on cancer services and excess 1-year mortality in people with cancer and multimorbidity: near real-time data on cancer care, cancer deaths and a population-based cohort study. BMJ Open 2020;10:e043828. 